УДК 621.396

\title{
ОЦЕНКА НАЧАЛЬНОЙ ФАЗЫ УЗКОПОЛОСНОГО РАДИОСИГНАЛА С НЕИЗВЕСТНЫМИ АМПЛИТУДОЙ И ДЛИТЕЛЬНОСТЬЮ*
}

\author{
А. П. ТРИФОНОВ, Ю. Э. КОРЧАГИН, М. В. ТРИФОНОВ, К. С. КАЛАШНИКОВ
}

Воронежский государственный университет, Россия, Воронеж, 394006, Университетская пл., д. 1

\begin{abstract}
Аннотация. Синтезированы квазиправдоподобный и максимально правдоподобный алгоритмы оценки начальной фазы радиосигнала с огибающей произвольной формы и с неизвестными длительностью и амплитудой. Предложены блок-схемы измерителей начальной фазы. Найдены характеристики синтезированных алгоритмов и выполнено сравнение точности оценок начальной фазы. Показано, что структура квазиправдоподобной оценки начальной фазы инвариантна к незнанию амплитуды радиосигнала, однако несовпадение ожидаемого значения длительности сигнала с его истинным значением может привести к заметному увеличению рассеяния квазиправдоподобной оценки начальной фазы. Определен проигрыш в точности оценки начальной фазы вследствие априорного незнания длительности сигнала. Показано, что аналитические выражения для статистических характеристик максимально правдоподобной оценки начальной фазы при больших отношениях сигнал-шум асимптотически совпадают с характеристиками максимально правдоподобной оценки начальной фазы радиосигнала с априори известными амплитудой и длительностью, а, следовательно, априорное незнание длительности сигнала асимптотически с ростом отношении сигнал-шум не влияет на точность максимально правдоподобной оценки начальной фазы. Методами статистического моделирования на ЭВМ определены границы применимости асимптотических выражений для характеристик максимально правдоподобной оценки применительно к сигналам с линейно и экспоненциально изменяющимися огибающими.
\end{abstract}

Ключевые слова: оценка максимального правдоподобия; квазиправдоподобная оценка; начальная фаза; длительность; амплитуда; смещение; рассеяние

Задача оценки начальной фазы радиосигнала, наблюдаемого на фоне шума, актуальна для многих практических приложений радиоэлектроники и неоднократно рассматривалась в литературе [1-10]. Так, например, необходимость детектирования фазоманипулированных (ФМ) сигналов, используемых в современных телекоммуникационных системах, требует формирования оценки начальной фазы. В $[1,2]$ рассмотрена максимально прав- доподобная (МП) оценка начальной фазы узкополосного радиосигнала при условии, что все остальные параметры сигнала априори известны, найдены характеристики оценки. В [3] исследованы способы построения когерентных демодуляторов ФМ сигналов на основе фазовой автоподстройки частоты несущего генератора опорного сигнала и на основе сдвига по фазе демодулируемого сигнала. Оценка на-

* Исследование выполнено за счёт гранта Российского научного фонда (проект № 17-71-10057).

DOI: $10.20535 / \mathrm{S} 0021347018060018$

(ㄱ А. П. Трифонов, Ю. Э. Корчагин, М. В. Трифонов, К. С. Калашников, 2018 


\section{БИБЛИОГРАФИЧЕСКИЙ СПИСОК}

1. Куликов, Е.И.; Трифонов, А.П. Оченка параметров сигналов на фоне помех. М.: Сов. радио, 1978. $296 \mathrm{c}$.

2. Тихонов, В.И. Оптимальный прием сигналов. М.: Радио и связь, 1983. 320 с.

3. Иващенко, П.В.; Перекрестов, И.С. “Оптимальная оценка фазы несущей при демодуляции сигналов цифровой модуляции," Цифровые технологии, № 6, C. 40-47, 2009. URI: https://ojs.onat.edu.ua/ index.php/digitech/article/view/660.

4. Харисов, В.Н.; Булавский, Н. Т.; Лупина, М. В. "Алгоритм оценки задержки на основе обработки фазы многочастотных сигналов," Радиотехника, № 7, C. 80-83, 2006. URI: https://elibrary.ru/item.asp?id=92 $\underline{33525 .}$.

5. Захаров, А.В. “Эффективность оценки фазы радиосигнала при наличии быстрых замираний," Вестник ВГУ. Серия: Физика. Математика, № 2, С. 221-228, 2010. URI: http://www.vestnik.vsu.ru/pdf/ physmath/2010/02/2010-02-30.pdf.

6. Гладких, Н. Д. “Оценка влияния допплеровского расширения полосы частот на ошибку оценки фазы гидроакустического (ГА) сигнала," Електроніка та зв'язок, № 6, С. 85-93, 2012. URI: http://elc.kpi. ua/old/article/download/11404/9742.

7. Noels, N.; Steendam, H.; Moeneclaey, M.; Bruneel, H. "Carrier phase and frequency estimation for pilot-symbol assisted transmission: bounds and algorithms," IEEE Trans. Signal Process., Vol. 53, No. 12, P. 4578-4587, 2005. DOI: 10.1109/TSP.2005.859318.

8. Yang, G.; Wang, J.; Zhang, G.; Shao, Q.; Li, S. "Joint estimation of timing and carrier phase offsets for

Поступила в редакцию 11.04.2016
MSK signals in alpha-stable noise," IEEE Commun. Lett., Vol. 22, No. 1, P. 89-92, 2018. DOI: 10.1109/LCOMM. 2017.2767031.

9. Ivanov, S. I.; Liokumovich, L. B.; Medvedev, A. $\mathrm{V}$. "Estimation of the parameters of the phase modulated signal in presence of the background noise using complete sufficient statistics," Proc. of XX IEEE Int. Conf. on Soft Computing and Measurements, SCM, 24-26 May 2017, St. Petersburg, Russia. IEEE, 2017, P. 11-13. DOI: 10.11 09/SCM.2017.7970480.

10. Chernoyarov, O. V.; Glushkov, A. N.; Litvinenko, V. P.; Litvinenko, Yu. V.; Matveev, B. V. "Fast digital algorithms for the coherent demodulation of the phase-shift keyed signals," Proc. of Conf. on Dynamics of Systems, Mechanisms and Machines, Dynamics, 14-16 Nov. 2017, Omsk, Russia. IEEE, 2017, P. 1-5, DOI: 10.1109/Dynamics.2017.8239444.

11. Трифонов, А. П.; Шинаков, Ю. С. Совместное различение сигналов и оченка их параметров на фоне помех. М.: Радио и связь, 1986. 268 с.

12. Тихонов, В.И. Статистическая радиотехника. М.: Радио и связь, 1982. 624 с.

13. Грязнов, М.И.; Гуревич, М.Л.; Рябинин, Ю.А. Измерение параметров импульсов. М.: Радио и связь, 1991. 216 с.

14. Корчагин, Ю.Э. “Оценка длительности радиосигнала с неизвестными амплитудой и фазой," $P a$ диотехника, № 9, C. 11-19, 2013. URI: http://radiotec. ru/article/13420.

15. Trifonov, A. P.; Korchagin, Yu. E.; Trifonov, M. V.; Chernoyarov, O. V.; Artemenko, A. A. "Amplitude estimate of the radio signal with unknown duration and initial phase," Appl. Math. Sci., Vol. 8, No. 111, P. 5517-5528, 2014. DOI: 10.12988/ams.2014.47588.

16. Трифонов, А.П.; Бутейко, В.К. "Характеристики совместных оценок параметров сигнала при частичном нарушении условий регулярности," Радиотехника и электроника, Т. 36, № 2, С. 319-327, 1991.

После переработки 04.04.2018 